\title{
The Presentation Pattern of Digital Learning Objects (Partial / Total) in an E-Learning Environment and It's Impact on Developing the Quality Skills of the Production of Educational Multimedia for Educational Technology Students
}

\author{
Bushra Al-Sayed Abdel-Majeed \\ Faculty of Specific Education, Alexandria University
}

\begin{abstract}
The current study aimed to measure the effect of Presentation Pattern of Digital Learning Objects (Partial / Total) in an ELearning Environment and on Developing the Quality Skills of the Production of Educational Multimedia for Educational Technology Students, and the research used the descriptive analytical approach And the semi-experimental approach, and the research tools consisted of an achievement test, a note card and the final product evaluation card, and the research sample consisted of a random sample of the second year students at the Faculty of Specific Education, Tanta University, consisting of (50) male and female students. (25) male and female students, where the first experimental group learned using the electronic learning environment based on partial digital learning objects, and the second experimental group learned using the electronic learning environment based on total digital learning objects, and the results of the research reached: There is a statistically significant difference at the level of significance ( 0.05$)$ between the average scores of the students of the first experimental group who used (the pattern of displaying digital learning objects (partial)), and the average scores of the students of the experimental group two who used (the pattern of displaying digital learning objects (Total)) in the post application of the achievement test related to the skills of multimedia production Educational in favour of the first experimental group, and the presence of a statistically significant difference at a level of significance $(0.05)$ between the average scores of the students of the experimental group The first group who used (Digital Learning Objects Display Pattern (partial)), and the average scores of the second experimental group students who used (Total Digital Learning Object Display Pattern) in the post application of the note card associated with the educational multimedia production skills in favour of the first experimental group, and the presence of A statistically significant difference at a level of significance $(0.05)$ between the average scores of the students of the first experimental group who used (the pattern of displaying digital learning objects (partial)), and the average scores of the students of the second experimental group who used (the pattern of displaying digital learning objects (Total)) in the post application the final product evaluation card in favour of the first experimental group.
\end{abstract}

Keywords: partial digital learning objects, total digital learning objects, an E-Learning Environment, the Quality Skills of the Production of Educational Multimedia, Educational Technology Students.

\section{Introduction}

With the continuous advancement of e-learning content design technology, many new patterns have emerged, especially with the growth and increase of digital content significantly, resulting in the need to reuse the content in different educational contexts; However, the image of content used in E-Learning environments was not suitable for re-use, Therefore, the need to divide the digital content into small parts called "Learning Objects" that can be reused in designing and building elearning content has emerged, where the digital
Educational content is divided into small components that address a single educational goal so that they can be reused in new educational situations and different context.

Thus, learning objects are a form of E-learning development. They are "digital learning resources" that can be reused in different educational situations, as every teacher and educational designer can use the learning object according to the requirements of the educational situation. 
Here, Meng et al. (Meng, et al., 2005, 5) indicate that Reusable Learning Objects (ROLs) have emerged as the next-generation technology for instructional design in the context of e-learning due to their "Reusability", "Modifiability", and "Interoperability". Harman and Khoohang (2013) believe that developing electronic content using learning objects has become a major requirement for designing electronic content, as the development of electronic content has become dependent on building standard learning objects, and collecting them in "e-Repositories" so that these objects form the basic unit for building the contents of various e-learning environments, not building complete electronic curricula and courses that are indivisible and reusable - as was the case before.

The The "E-Repositories" are a digital entity that plays the role of a repository with an internal retrieval feature and some research facilities, with another feature, which is the "Metadata" that facilitates access to the appropriate learning objects that enable all users to access their needs and requirements easily, where those repositories storing, cataloguing and classify learning objects.

Ritzhaupt (2010) believes that digital learning objects should not be seen as media that allows designers and developers to share electronic content, thus only effectively reducing the cost of education. But there is an important issue that designers and developers must bear in mind which is, do learning objects as small units have their own characteristics provide a better opportunity to improve learning and obtain high-quality education compared to other forms of content presentation? In other words, does the existence of learning objects as a basis for the structure of e-learning environments, per se, can allow for better learning? This question is followed by another question, is it possible to improve the performance of Learning Objects? Here, "Ritzhaupt" indicates that learning objects must be thought of as gears that work within a large machine. When properly installed, arranged and managed, they lead to an improvement in the learning process, therefore, Learning objects alone may not improve learning, but their work within an appropriate learning system or environment appropriately employs these elements and may contribute positively to improve learning.

The results of many studies and research have confirmed the effective impact of E-learning environments based on learning objects in achieving various learning outcomes, including: (Tuvi-Arad \& Gorsky, 2007, Hamza -Lup, Stefan, 2008; Sun, Horng, Liu, \& Tien, 2009; Salajan, et, 2009, Dalgarno \& Lee, 2010; Hesse \& Gumhold, 2011, the study of Ahmed Muhammad Nubi Saeed, 2009; Rayma Rashid Al-Ahmari 2010, Nader Saeed Shimi 2010, Ismail Hassouna et.al, 2013; the study of Rida Ibrahim Abdel-Maaboud, 2014; and the study of Walid Yousef Mohamed Ibrahim 2014). The Researchers also called for further studies on the elements influencing the design of e-learning environments based on learning objects.
In this context, Mohamed Abdel Hamid Ahmed (2013) indicates that we need studies concerned with designing the variable content presentation and submit it in elearning environments. Harman and Khoohang (2013) assure that the content presentation pattern has a significant impact on determining the learning path, and the content may lose its effectiveness, not because it is unsound, but the pattern or style of its submission makes the learning difficult, and according to both (Haughey \& Murihead, 2010; Ritzhaupt, 2010; and Harman \& Khoohang, 2013), they believe that we need more studies that deal with determining the appropriate pattern to display learning objects in light of the determinants and nature of the E-learning environment used.

Here, many literature and researches in the field of designing electronic learning environments based on learning objects (Nader Saeed Shiemi, 2010, 300; Ritzhaupt, 2010; Haughey \& Muirhead, 2010; Harman \& Khoohang, 2013; Walid Youssef Muhammad Ibrahim, 2014) indicate the existence of Different styles of designing electronic learning environments based on learning objects differ and vary in size and level of detail, among which there are two basic patterns that we can choose one of them to be the basis of the content structure of the e-learning environment, namely:

The first pattern: Partial learning object / "The step":

It's considered the smallest integrated learning entity includes all components of the learning process where the structure of Reusable Learning Objects (RLOs) consists of Objective, Content, Activity, Evaluation and Summary, which may also contain a dictionary of terminology, and that within the limits of a number ( $7 \pm$ 2) of information units or reusable elements (RIO), and building learning objects based on a specific educational goal.

The second pattern: total / "lesson":

The entity that includes more than one learning object together (Steps) and takes into consideration the increased number of objectives, activities, evaluations and other components of the learning process in proportion to the number of objects or steps that make up the lesson.

Both patterns have scientific views and theories that support them. The first pattern, which involves the fragmentation of content into very small parts called learning objects, is directly and explicitly supported by one of the basic principles of "Information Processing Theory," namely, the concept of "Chunking" and its relationship to the short-term memory capacity, "Chunking" is the process of dividing information into small units or parts, called a thesaurus. A thesaurus is any meaningful unit, which may be numbers, words, pictures, drawings, or anything else. The short-term memory has a limited capacity, it can only retain a number of $(5-9)$ the Information thesauri $(2+7)$, and can increase the capacity of this memory and facilitate the process of remembering if the information is divided (Muhammad Atiyah Khamis, 2013, 206). 
The main goal of any learning process is to easily submit the content or educational syllabus to students, without causing them any boredom, but rather increases their attraction and desire for the educational process, this goal is not achieved with the required success unless the student uses more than one sense in the education process so that the learning will have the remaining effect, this is done through the use of more than one tool or media through which students learn, especially if this medium is provided to them through an electronic device such as a computer, as the computer is one of the most important components of our current era, where this computer has become included in all aspects of life and all the fields, Therefore, it has been used in the educational process to enrich the learning process and to attract and excite the students for education through its programs, and the most important of these programs on which the computer is based when it is used in education are multimedia programs, and these programs are seen as an element of attraction and excitement for students to learn, thus increasing their motivation for the educational process as a whole (Jamal Mustafa Abdel-Rahman AlSharqawi, Hasnaa Abd Al-Ati and Ismail Al-Tabbakh, 2013, 19).

The importance of multimedia in the teaching and learning processes stemmed from the fact that it helps to stimulate the student's interest, satisfy his need for learning, and increase the student's experience, making him more willing to learn and engage all his senses, the diversification of educational aids also leads to the formation of sound concepts that help increase the positive participation of the student in gaining experience, and diversifying the reinforcement techniques that lead to stabilization of the correct responses (Skinner's theory), and the diversification of the educational methods to face individual differences between learners, which leads to modifying behaviour and forming new trends (Abdulaziz Talibah Abdul Hamid, 2011, 55).

The interest in the concept of multimedia teaching and learning came as a result of an effective shift in educational thought from the pattern of collective educational situations to those individual attitudes, and from the focus in evaluating the learner on memorizing the content of the school subject to an evaluation that measures how much skills the learner gains, and the educational goals he achieves, this interest also came as a result of the change of the teacher's role, as his role is no longer limited to transmitting the scientific and educational heritage to his students, but rather he is required, more than ever before, to deal with devices, tools, and modern educational resources, designing them and making use of their functions and capabilities, to increase the effectiveness of educational situations and its efficiency.

The use of the term "multimedia" comes mainly to distinguish between what is traditional and what is modern in learning, according to the first: he sees the individual as just a mind into which information is poured only, and he is merely a recipient, so the reliance on science and textbook, as for the modern view, it considers the individual as a living, interacting organism, and its goal is its growth and maturity, and the goal is not to memorize information, but rather build the individual knowledge according to his handling of it. Given that the individual builds his knowledge and not a negative recipient for it (Kamal Abd-Al-Hamid Zaitoun, 2004, 67), the current research is concerned with developing the quality of educational multimedia production skills among educational technology students.

\section{Methodology:}

\section{Study Problem:}

The current research problem is the need to identify the most appropriate pattern of content presentation in elearning environments based on learning objects (Partial learning objects/total), concerning their impact on learning skills in both aspects: performing, cognitive and access to the quality of students production related to educational multimedia.

\section{Study Questions:}

To solve the research problem, the current research seeks to answer the following main question:

How can an E-learning environment be designed based on the displaying pattern of Digital Learning Objects (partial/total) to develop the skills of the educational multimedia production quality among educational technology students? From this main question several sub-questions stemmed from:

1) What are the educational multimedia production quality skills that must be developed for educational technology students?

2) What are the educational multimedia production quality standards?

3) What is the proposed educational design for designing an E-learning environment based on the displaying pattern of Digital Learning Objects (partial/total) to develop the educational multimedia production quality skills for educational technology students?

4) What is the effect of the digital learning objects presentation (partial/total) in the E-learning environment on the development of the cognitive aspect associated with the educational multimedia production skills for the educational technology students?

5) What is the effect of displaying digital learning objects (partial/total) in the E-learning environment on the development of the performance side of the educational multimedia production skills for the educational technology students?

6) What is the effect of the digital learning objects display pattern (partial/total) in the E-learning environment on the educational multimedia production quality among the educational technology students? 
Objectives:

The research aimed to determine the most appropriate content display pattern in e-learning environments based on learning objects (Partial learning objects/total), concerning their impact on learning skills in both aspects: performing and cognitive and access to the quality of students production related to educational multimedia through detection About:

1) The list of educational multimedia production quality skills that must be developed for educational technology students.

2) The list of educational multimedia production quality standards.

3) The proposed design for designing an E-learning environment based on the displaying pattern of Digital Learning Objects (partial/total) to develop the educational multimedia production quality skills for educational technology students.

4) The effect of the digital learning objects presentation (partial/total) in the E-learning environment on the development of the cognitive aspect associated with the educational multimedia production skills for the educational technology students.

5) The effect of displaying digital learning objects (partial/total) in the E-learning environment on the development of the performance side of the educational multimedia production skills for the educational technology students.

6) The effect of the digital learning objects display pattern (partial/total) in the E-learning environment on the educational multimedia production quality among the educational technology students.

\section{Significance of Study:}

The research results may contribute to the concerned university educational institutions adopting new strategies, patterns and tools for designing E-learning environments, seeking to improve the level of different learning outcomes.

- This research presents a model for E-learning environments based on learning objects used to teach skills.

- $\quad$ Research results may contribute to enhancing the use of the potential of some electronic environments to overcome the difficulties of Educational technology students in studying educational curricula.

- The results of this research may contribute to providing designers and developers of E-learning environments with a set of scientific principles and foundations when designing such environments, concerning the use of appropriate patterns of displaying learning object for the development of both cognitive and performance aspects in some curricula.

- The results of this research may serve to provide some of the scientific foundations and principles embedded in the design of E-learning environments based on learning objects designed for curricula that incorporate the cognitive and performance aspects.

limitations:

The current research has remained within the following limits:

1) Human boundaries: Students of the first year in the Education Technology Department.

2) Objectivity border: Multimedia approach.

3) Temporal boundaries: The first semester of the 2019/2020 academic year.

4) Spatial boundaries: Faculty Of Specific Education, Tanta University.

\section{Terminology:}

\section{E-learning environment:}

The researchers define it procedurally -in this research- as an environment that aims to provide electronic content using digital learning objects, simultaneous and asynchronous interaction tools to develop educational multimedia production quality skills among educational technology students.

\section{Digital Learning Objects:}

The researchers define it procedurally -in this research- as "multi-media digital sources or information units of digital material in the form (text, sound, image, static and animation graphics, and interactive tools) some or all of them come together to design content service, prepare learners and stimulate their learning, using them in a variety of educational contexts according to the learning objectives to be achieved, which relate to the development of educational multimedia production quality skills among educational technology students.

\section{Partial digital learning objects:}

In this research, researchers define it as the smallest integrated educational entity that includes all components of the learning process, as this pattern includes six main components, (1) the goal of the educational object, (2) learning (content) through which the educational content is presented from Through a variety of media used (audio, visual, ...), (3) activities, through which a number of diverse interactive activities complementary to learning are presented and that contribute significantly to learners' learning more deeply, (4) self-evaluation, Through it the presentation of a question or a number of substantive questions, taking into account the provision of direct, immediate and targeted responses, (5) the glossary of terms, and includes a list of terms that were presented in the educational content in alphabetical order, (6) the summary, and provides a comprehensive summary of what was presented with the educational content related By developing the quality of educational multimedia production skills among educational technology students.

\section{Total Digital Learning Objects:}

The researchers define it procedurally - in this research that it's the entity that includes more than one partial 
learning object (step), and it includes the same previous components, taking into account the increase in the number of goals, activities, evaluations and other components of the learning process in proportion to the number of objects included in the "lesson" associated with the development of the educational multimedia production quality skills among educational technology students.

\section{Educational multimedia:}

Researchers define it procedurally - in this research - as electronic programs that include text and image whether the situation is static or dynamic, audio and video through which certain scientific content is provided that students of educational technology can interact with through a computer, to achieve a set of specific educational goals.

\section{Procedures:}

\section{Society and Research sample:}

The sample community consists of all students of the Department of Educational Technology, Faculty of Specific Education, Tanta University, and the research sample consisted of a random sample of students of the second year of the Faculty of Specific Education, Tanta University, consisting of (50) male and female students. They were divided into two experimental groups of equal number, each group consisting of (25) male and female students, where the first experimental group learned using the E-learning environment based on partial digital learning objects, and the second experimental group learned using the E-learning environment based on total digital learning objects.

\section{Study Instruments:}

Researchers have developed the following research tools: 1. An achievement test to measure the cognitive aspect of educational multimedia production quality skills.

2. Student note card for the performance side of multimedia production skills.

3. A product evaluation card to measure the quality of students' production of educational multimedia.

Study Variables:

The current research included the following variables:

1. The independent variable: the pattern of displaying digital learning objects (partial/total) in the Elearning environment.

2. The two dependent variables:

a. The Cognitive aspect of educational multimedia production quality skills.

b. Educational multimedia production quality skills.

\section{Study Methodology:}

This research belongs to the category of researches that use descriptive approach designs in the study, analysis and design phase, and the semi-experimental approach when measuring the effect of the independent variable of the research on its dependent variables in the evaluation phase.

\section{Hypotheses:}

The current research sought to verify the validity of the following hypotheses:

H.1 There is no statistically significant difference at a level of significance $(0.05)$ between the average scores of the first experimental group students who used (the pattern of displaying digital learning objects "partial") and the second experimental group's average scores who used (the pattern of displaying digital learning objects "total") in Post application of the achievement test related to educational multimedia production skills.

H.2. There is no statistically significant difference at a level of significance $(0.05)$ between the average scores of the first experimental group students who used (Digital Learning Objects Display Pattern "partial") and the second experimental group's average scores who used (Digital Learning Objects Display Pattern "total") in the post application of the note card associated with educational multimedia production skills.

H.3. There is no statistically significant difference at a level of significance $(0.05)$ between the average scores of the first experimental group students who used (Digital Learning Objects Display Pattern "partial") and the second experimental group's average scores who used (Digital Learning Objects Display Pattern "total") in the post application of the final product evaluation card.

\section{Results \& Discussion}

\section{The current research reached the following results:}

1) There is a statistically significant difference at a level of significance $(0.05)$ between the average scores of the first experimental group students who used (the pattern of displaying digital learning objects "partial") and the second experimental group's average scores who used (the pattern of displaying digital learning objects "total") in Post application of the achievement test related to educational multimedia production skills in favor of the first experimental group.

2) There is a statistically significant difference at a level of significance $(0.05)$ between the average scores of the first experimental group students who used (Digital Learning Objects Display Pattern "partial") and the second experimental group's average scores who used (Digital Learning Objects Display Pattern “total") in the post application of the note card associated with educational multimedia production skills in favor of the first experimental group.

3) There is a statistically significant difference at a level of significance $(0.05)$ between the average scores of the first experimental group students who used (Digital Learning Objects Display Pattern "partial") and the second experimental group's average scores who used (Digital Learning Objects Display Pattern “total") in the post application of the final product evaluation card in favor of the first experimental group. 
4) These findings indicate that students who have studied through the Partial Learning Objects pattern have been more positive in learning the cognitive aspect of the skill, skill performance and quality of the final product of the educational multimedia than students who have studied through the pattern of total learning objects in general, and therefore this result must be taken into consideration when designing E-learning environments based on learning objects, especially if the results of future studies and research support this result.

The researchers attribute this result to the following reasons: According to the researchers, the main reason for the superiority of the Partial Learning Object pattern over the total learning object pattern is that the division of content into small, specific parts of a learning object with limited content and associated with a specific goal, activity and performance evaluation, has enabled the student to experience learning before moving to new experience and linking them together.

In the current research, researchers have also sought to provide a great deal of competence in designing learning objects and selecting their content, so that each object consists of a coherent part expressing an independent entity that can be separated and linked to other learning objects, to avoid what was indicated by (Ritzhaupt, 2010) that It should not be believed that the existence of learning objects as a basis for the structure of e-learning environments, per se, can allow for better learning. Rather, learning objects must be thought of as gears that work within a large machine. When properly installed, arranged and managed, they lead to an improvement in the learning process, therefore, Learning objects alone may not improve learning, but their work within an appropriate learning system or environment appropriately employs these elements and may contribute positively to improve learning.

This result is consistent with the study of Francis and Murphy (2008), which showed the effectiveness of digital learning objects better in assessing the performance of learners with their reusability compared to educational modules; It also agrees with the results of the Mercado, Anderson and Reynoso study (2008), whose results indicated the superiority of educational objects over the prevailing method used by the teacher (Teacher-led traditional instruction) in developing the skill performance of using the "C ++" language among undergraduate students in computer science, It also agrees with the results of the Looser study (2009), which showed an increase in the number of science teachers in the United States of America who use educational objects compared to the number of users of educational modules; The results of the study also demonstrated the effectiveness of digital learning objects in providing immediate feedback, which helped to improve students' performance in the science, then the study concluded that digital objects are an effective application of constructivism theory because they can be modified by the learner according to his needs, This result is also consistent with the results of the Halah Abdel Monim Mohamed Saleh study (2012), which resulted in the group studied using educational objects being superior to the set of educational modems in both cognitive attainment and skilled performance; It also agrees with the results of Walid Youssef Mohamed Ibrahim (2014), whose results have resulted in the group that studied using separate learning objects being superior to the group of learning objects "lesson"; The results of the Ismail Omar Hassouna et al. (2016) study also confirmed the effectiveness of the educational web program based on binary and three-dimensional learning objects in developing skills to use educational technology tools.

This result differs from the results of the Nader Said Shimei study (2010), whose results indicated that there are no statistically significant differences between the two patterns of separate learning objects and the pattern of lessons in cognitive achievement among students with low achievement motivation.

Partial-learning objects have thus introduced a new pattern of digital content presentation that can present many courses more effectively and efficiently.

\section{Recommendation}

In light of the research findings, their discussion and interpretation, the researchers recommend the following:

1) Make use of the results of the current research at the applied level, especially if future research supports these results.

2) Benefiting from the results of previous studies and research that dealt with studying the effect of some variables of designing E-learning environments based on learning objects and producing them on different learning outcomes when designing and producing these environments.

3) Make use of the results of previous studies and research that dealt with studying the effect of multiple variables for the design of electronic environments based on learning organisms, and their production on different learning outcomes when designing and producing these environments.

4) Adopting an educational design model when preparing for the production of electronic environments based on learning objects and their production. The multiplicity of these models allows choosing the appropriate model for the production team and the available capabilities.

\section{Suggestions}

In light of the current research results, and by reviewing previous studies related to the research topic, researchers suggest the following research topics:

1-It is noticeable that most of the empirical research that is concerned with studying the impact of one or more variables in the design of E-learning environments in general, and electronic environments based on learning objects specifically, include short treatments. This puts several restrictions on generalizing its results despite their validity, and this requires adopting the approach 
of repeated research, and accordingly, the current research recommends the necessity of re-conducting the current research by researchers in different study subjects as a prerequisite for generalization

2-The current research was limited to dealing with the effect of its independent variables on educational technology students, so future research may address these variables within the framework of other educational stages, and the results may differ due to the difference in age and level of experience.

3-The current research has not been exposed to studying the relationship between its processors in light of their interaction with the learners' preparations, so future research may address the same independent variables for the research in the context of their interaction with cognitive methods or other preparations of learners related to skills learning, including, for example, autonomous versus dependent cognitive method, and the unrealistic experience or an integrative installation method.

\section{References}

[1] Abdulaziz Abdulhamid (2011). The effect of the difference in the design of the web-based learning environment using the digital learning units repository in the educational technology course on the achievement and production of multimedia software among students of the College of Education. Studies in Curricula and Teaching Methods: Ain Shams University - Faculty of Education - Egyptian Association for Curricula and Teaching Methods, p. 167, p. 42 - 87.

[2] Ahmed Saeed (2009) The Effectiveness of Designing Electronic Learning Objects for Blended Learning on the Achievement and Attitudes of Medical Students at the Arabian Gulf University, Journal of Educational Technology: Studies and Research, 19 (14), vol. 1 April, 153-170.

[3] Al-Ajili Sarkaz, Naji Khalil (2010) Education Theories, Benghazi, Qar Younis University Publications.

[4] Al-Gharib Ismail (2009) Electronic Courses: Designing - Producing - Publishing - Applying Evaluating, Cairo, World of Books.

[5] Dalgarno, B., \& Lee, M. J. W. (2010). What are the learning affordances of 3-D virtual environments? British Journal of Educational Technology, 41(1), 10-32. doi: 10.1111/j.1467-8535.2009.01038.x

[6] Francis, D. \& Murphy, E (2008). Instructional Designers' Conceptualization of Learning Objects. Australasian Journal of Educational Technology. 24(5), 475-486.

[7] Hala Saleh (2012) The impact of the different pattern of delivering electronic courses via the Internet on the development of cognitive achievement and skill performance among first-year preparatory students in computer subject, Master's thesis, Faculty of Education - Ain Shams University.
[8] Hamza -Lup, F. \& Stefan, V. (2008). Web 3d \& Virtual Reality - Based Applications For Simulation And E-Learning. International Conference On Virtual Learning - Www.Icvl.Eu

[9] Harman, K \& Khoohang, A (2013) Learning Objects: Applications, Implementations \& Future Directions, California, Information science Press

[10] Haughey, M. \& Murihead, B (2010) Evaluating Learning Objects for Schools. Doctor degree, University of Ontario, Institute of Technology.

[11] Hesse, S., \& Gumhold, S. (2011). Web based Interactive 3D Learning Objects for Learning Management Systems. Chair of Computer Graphics and Visualization, Technische Universitat DresdenD01062 Dresden, Germany.

[12] Ismail Hassouna, Abdel Latif Al-Jazzar, Mohamed Khamis, Yehia Abu Jahjouh, and Nevin Mohamed El-Sayed (2013) Designs of two-dimensional / threedimensional learning objects in a web-based program, and their impact on the development of skills in using educational technology tools: an empirical study at the Faculty of Education - AlAqsa University , Journal of Educational Technology, Studies and Research Series 23 (3) April, 3- 57.

[13] Jamal Al-Sharqawi and Hasna Al-Tabbakh (2013). The effect of different navigation patterns for mobile learning programs in developing the skills of designing and producing electronic multimedia programs for postgraduate students in the College of Education. Arab Studies in Education and Psychology: The Arab Educators Association, Volume 35, Part 4, pp. 13-74.

[14] Kamal Zeitoun (2004). Education technology in the information and communication age. Cairo: The world of books.

[15] Looser, T (2009), Fetch, Plug, and Play: How Secondary Science In Structors use Digital Learning Objects in their Classrooms. Ph.D Dissertation, Capella University.

[16] Meng, A. et al (2005): A Multi-Agent Enabled EEducation Object and Course Authoring System (MEEOCAS), INTERNATIONAL JOURNAL OF INSTRUCTIONAL TECHNOLOGY AND DISTANCE LEARNING , 2 (8), August, Retrieved from: http://www.itdl.org/Journal/Aug_05/Aug_05 .pdf) viewed in 8/12/2010.

[17] Mercado, C, Andrade, E \& Reynoso, J(2008) The Effect of Learning Objects on a C++ Programming Lesson, San Diego, Proceedings of the 19 th Annual International Information Management Association, 13-15 October,77- 84, http://www.codewitz.net/

[18] Mohamed Ahmed (2013) Scientific Research in Educational Technology. Cairo, the world of books.

[19] Muhammad Khamis (2011). Teaching and Learning Technology, Cairo, Dar Al-Sahab Library.

[20] Muhammad Khamis (2013) Theory and educational research in educational technology, Cairo, Dar AlSahab for printing, publishing and distribution. 
[21] Muhammad Khamis (2018). E-learning environments, Cairo: Dar Al-Sahab.

[22] Nader Shimi (2010) The effect of motivational design of some types of electronic learning elements on the achievement and development of motivation among students with low achievement motivation, Journal of Educational Technology: Studies and Research, 20 (2) April, 300-340.

[23] Reda Ibrahim (2014) The effectiveness of a proposed model for employing e-learning based on learning objects in the achievement of educational technology students and their attitudes towards it, $\mathrm{PhD}$ thesis, Faculty of Specific Education - Ain Shams University.

[24] Rima Al-Ahmari (2010). The effectiveness of using learning objects in developing the academic achievement of first-grade intermediate students in teaching English language. Master's Thesis - King Abdulaziz University - Saudi Arabia.

[25] Ritzhaupt, A (2010) Learning Object Systems and Strategy: A Description and Discussion. Interdisciplinary Journal of E-Learning and Learning Objects (6), 217-238

[26] Robert Solso (2000) Cognitive Psychology, translated by Muhammad Naguib Al-Sabwa and others, 2nd edition, Cairo, Anglo-Egyptian Library.

[27] Salajan, F. D., Perschbacher, S., Cash, M., Talwar, R., El-Badrawy, W., \& Mount, G. J. (2009). Learning with web-based interactive objects: An investigation into student perceptions of effectiveness. Computers \& Education, 53(3), 632643. doi:10.1016/j.compedu.2009.04.006

[28] Sun, T.-H., Horng, H.-C., Liu, C.-S., \& Tien, F.-C. (2009). Invariant 2D object recognition using KRA and GRA. Expert Systems with Applications, Vision research journal, www.elsevier.com/locate/visres, 36(9), 11517-11527. doi:10.1016/j.eswa.2009.03.055

[29] Takaya \& Keiichi. (2008). Jerome Bruner's Theory of Education: From Early Bruner to Later Bruner. Journal Articles; Opinion Papers, 39(1), PP. 1-19.

[30] Tuvi-Arad, I., \& Gorsky, P. (2007). New visualization tools for learning molecular symmetry: a preliminary evaluation. Chemistry Education Research and Practice, 8(1), 61.

[31] Walid Ibrahim (2014). The interaction between content presentation patterns in e-learning environments based on learning objects and tools for navigating them and its impact on developing database management skills, and the usability of these environments among secondary school students, Egyptian Association for Educational Technology, 24 (1), pp. 3-88. 